\title{
Tender Evaluation by Visual Decision Support System
}

\author{
Prof. Rajiv Gupta, Leela Krishna Kondepati, and Dr. Anu Gupta
}

\begin{abstract}
The process of evaluating tenders is a multi-criteria decision making process in which project performance is influenced by cost, time and quality. It involves a wide range of criteria, which are not only quantitative but can also be defined qualitatively. The present paper deals with visual decision support system, which can consider such criteria to evaluate the tenders. With the help of the proposed decision support method, the uncertainty of criteria can be reduced. By using two case studies the tender evaluation is then fully investigated using Visual decision support system approach.
\end{abstract}

Keywords - Tender evaluation, Visual decision support system, Multi criteria decision analysis

\section{INTRODUCTION}

$\mathrm{T}$ ENDER evaluation is always an important and essential task for owner and client. It not only involves quantitative criteria, like monetary costs and benefits but also qualitative and intangible factors such as managerial, safety accountability, competence, and efficiency of contractors, etc. (Fuzzy) [2] [33]. The number of factors will vary from project to project and expert to expert. If the number of well-defined factors can be spelled out precisely and their evaluation procedure without any uncertainty, the act of evaluation may not be as difficult as it is without them [3]. This was observed by authors by doing a simple exercise. To evaluate the performance of speakers in class seminars on technical matter, a set of students was asked to mention the criterion they will consider for evaluation purpose. After selecting the number of criterion from the set of criterion thus obtained, the final selected set of criterion was given to another set of students. It was observed that the numbers of factors keep on increasing largely. However, the expert may neglect some factors completely and some factors may be considered with small weightage as compared to other factors. It is quite clear that any evaluation technique will have number of factors with different weightages [4] [5] [8] [9].

The process of evaluating tenders can be done using Fuzzy sets (Zadeh 1965), Multi criteria decision making (Zimmerman 1985), Evidential Reasoning approach (Smita sarker), Analytical Hierarchy Process (Satty 1980), TOPSIS (Hwang \& Yoon 1981) [1] [6] [7] [25] [26] [33] [35].

Prof. Rajiv Gupta is with Civil Engineering Department, Birla Institute of Technology and Science, Pilani, India.

Leela Krishna Kondepati, Ex student, is with Civil Engineering Department, Birla Institute of Technology and Science, Pilani, India.

Dr. Anu Gupta is with Electrical and Electronic Engineering Department, Birla Institute of Technology and Science, Pilani, India.
This paper deals with a decision support system, which can consider the entire criterion into account directly or indirectly with only important factors into consideration. The reason of presenting a visual decision support system is its visuality, multi dimensionality and simplicity in understanding. Another important aspect of the method is its convertibility from one dimension to two and three dimensions or other way and linear to nonlinear or the other way. When an exercise was given to some evaluators, initially they find some difficulties in presentation. However, it was overcome after few numbers of repetitions [33] [10] [12] [13] [14] [15].

The paper deals with single dimensionality and converting dual and triple dimensionality into one. Other aspect can be easily incorporated. It also deals with the change from linearity to non-linearity. For simplicity purpose the number of factors to evaluate is kept low and is taken directly from the ref. [33].

\section{Multi CRITERIA TENDER SELECTION}

In a tender evaluation process, the owner-client holds the meetings with ones associates to exchange individual assessments on various tenders. Each partner gives a rating table for each factor for each contract. A factor may have different values for different projects. The group may go for pessimistic aggregation [33] i.e.

$$
\mu_{i}=\mu_{i j}^{1} \cap \mu_{i j}^{2} \cap \mu_{i j}^{3} \cdots
$$

Or optimistic aggregation,

$$
\mu_{i}=\mu_{i j}^{1} \cup \mu_{i j}^{2} \cup \mu_{i j}^{3} \cdots
$$

Both have got some advantages and disadvantages (Hipel, Znotives \& Hipel) [33].

\section{A. One to one Dimension}

Here the membership value of each factor is defined by the diameter of the circle whose diameter is unity, i.e., $\mu=0.68$ is represented by a circle which is filled by a colour up to 0.68 of its diameter from the bottom (Fig.1). 


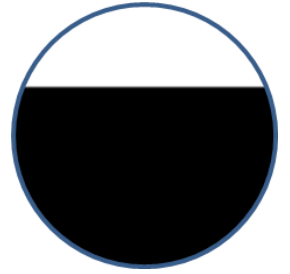

Fig. 1 One dimensionality

i. Scenario A: Assume we have to choose among five tenders, $\mathrm{A}=\{\mathrm{x} 1, \mathrm{x} 2, \mathrm{x} 3, \mathrm{x} 4, \mathrm{x} 5\}$ the most suitable contractor who satisfy the entire principle criterion. Let $B=\{y 1, y 2, y 3\}$ be the set of criterion of equal importance, being [33]

TABLE I

INITIAL RATING MATRIX OF BINARY RELATION A X B

\begin{tabular}{c|l|l|l}
\hline$x_{1}$ & $y_{1}$ & $y_{2}$ & $y_{3}$ \\
$x_{2}$ & 0.68 & 0.50 & 0.90 \\
$x_{3}$ & 0.94 & 0.70 & 0.67 \\
$x_{4}$ & 0.88 & 0.90 & 0.72 \\
$x_{5}$ & 0.78 & 0.92 & 0.79 \\
\hline
\end{tabular}

The corresponding matrix in proposed method is shown in table 2

TABLE II

Rating Matrix A X B Using Visual DeCision SUPPoRt Method

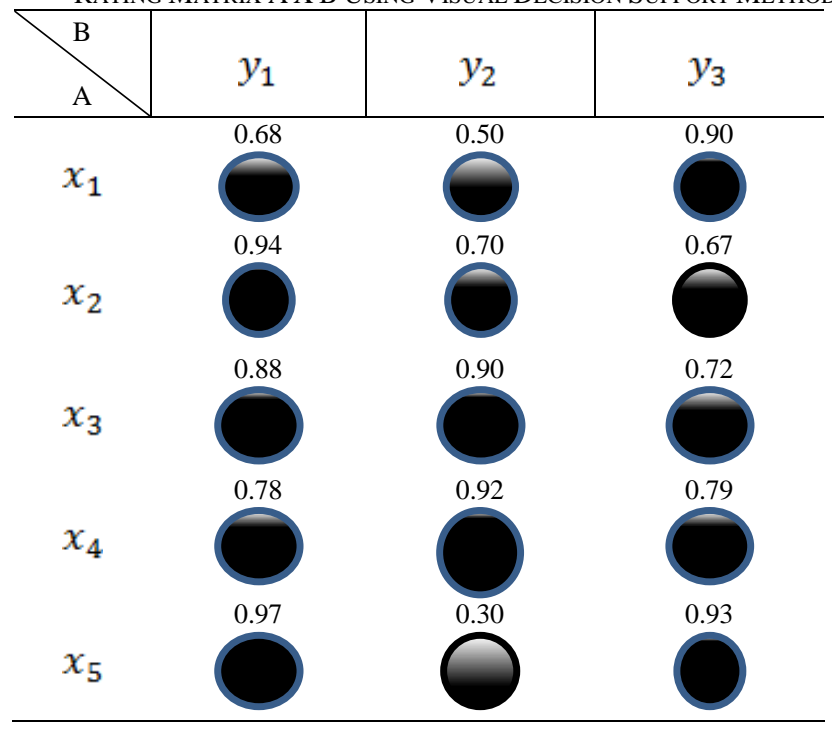

The above matrix can always be modified as in case of RE. [33] with limits of membership grades or ratings of (0.92 and 0.30 ). If these memberships are superimposed, it is clear that $\mathrm{x} \_4$ will be selected because it has got the maximum area covered by a single colour. Another important aspect is if the colors with factors are standardized, the final circle will give the complete picture of factors which are fulfilled by a contractor up to what extent and the complex matrices need not be looked at.

ii. Scenario $B$ : If the selection board decides to give different weightages to the different factors, it can be easily incorporated in proposed method. For example if the weightages of various factors are now different, then Table 2 shows the corresponding result. The weightages can either be given by membership value or directly [33].

TABLE III

RATING Matrix A X B (DifFERENT Weights) Using Visual DeCISION SUPPORT METHOD

\begin{tabular}{l|l|l|l}
\hline & $y_{1}$ & & $y_{2}$ \\
\hline$x_{1}$ & & & \\
\hline
\end{tabular}

\section{B. Dual Dimensionality to Single Dimensionality}

As mentioned in the introduction that for an evaluation of any tender, all the factors cannot be taken into consideration. However, some auxiliary factors can always be clubbed together and considered as one principle factor.

To represent the membership grade, instead of taking diameter of circle as membership value, circle of unit area is taken into account and the diameter of the circle is obtained. For example membership grade $=0.68$ represents 0.68 \unit』 $\wedge 2$ area and the corresponding percentage of filling is $73 \%$. Degree of accuracy can also be achieved by taking more number of points after decimals. All the above operations can be carried out either

a) Changing the membership into corresponding diameters and then performing the operations.

b) Performing the operations first and then convert it into single membership grades.

Membership grades are converted using below expression

$$
\begin{aligned}
& A=\frac{R^{2}}{2} \times(\theta-\sin \theta) \\
& h=R\left(1-\cos \left(\frac{\theta}{2}\right)\right)
\end{aligned}
$$

Here,

$\mathrm{A}$ is equal to the membership grade in single dimensionality

$\mathrm{R}$ is the radius of circle when its area is equal to $1(\mathrm{R}=0.564)$

$\theta$ is the sector angle

$\mathrm{h}$ is the height of filling from bottom 
It may be said that ultimately all membership grades are being converted from unit area $(\mathrm{d}=1.128)$ into unit diameter. But it is not a nonlinear relation. It is very obvious that this conversion is qualitative based and not quantitatively based.

\section{Triple Dimensionality to Single Dimensionality}

To represent the membership grade, instead of taking diameter of circle as membership value, sphere of unit volume is taken into account and the diameter of the circle is obtained. For example membership grade $=0.68$ represents 0.68 \unit】^3 volume and the corresponding percentage of filling is $77 \%$. Degree of accuracy can also be achieved by taking more number of points after decimals.

Membership grades are converted from triple dimensionality to single dimensionality using below expression

$$
v=\pi \times \frac{h^{2}}{3} \times((3 \times r)-h)
$$

Here, $\mathrm{V}$ is the membership grade in single dimensionality $\mathrm{R}$ is the radius of sphere when its volume is $1(\mathrm{R}=1.24)$ $\mathrm{h}$ is the height of filling from bottom.

It may be said that ultimately all membership grades are being converted from unit volume $(d=1.24)$ into unit diameter. But it is not a nonlinear relation. It is very obvious that this conversion is qualitative based and not quantitatively based.

Virtual decision support system approach is briefly explained in the following case studies.

\section{CASE STUDY-1}

"Aakash Ganga" (or "River from the sky" in Hindi) is a rainwater harvesting project to assist villages in rural India that have little access to clean water. The program is based on a public utility model, where every homeowner in the community with adequate sized roof is asked to lease the rights to harvest their rooftop rainwater. They are provided with the gutters, spouts and pipes that are connected to a network of interconnected underground storage reservoirs.

Aakash Ganga IT Network (ITN) aims to capture, store and disseminate information for development, design, upkeep, and scale up of Aakash Ganga network. It is analogous to a singlestop store for all the materials that a builder may need to build a house or a place. The dissemination of information will, it is envisaged, earn community trust [11].

The four agencies Tender 1, Tender 2, Tender 3, and Tender 4 have sent proposals for development of the online database required for the Aakash Ganga Rainwater Harvesting Network. We apply Virtual Decision Support system to analyze the performance of four types of tender. Here both qualitative and quantitative performance attributes are considered for demonstrating purpose. The major performance attributes are considered as Software used, Database used, and Time for host on server, Economic Aspect, Experience [11] which we shown on fig 2 .

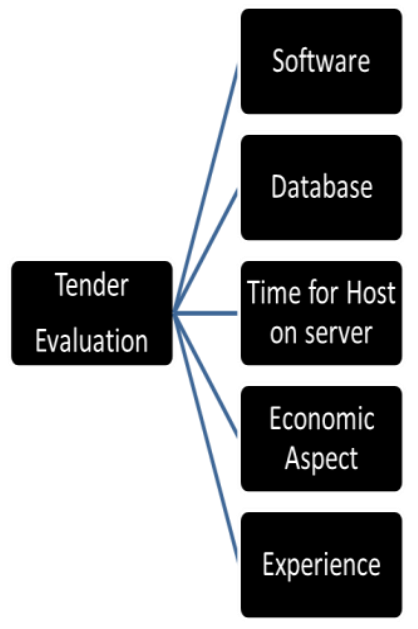

Fig. 2 Attributes chart Case study-1

A. Computational Steps of Aggregating Assessment:

a) The above case study was solved for all the three cases (i.e. for single, dual and triple dimensionality).

b) In the case of single dimensionality firstly major attributes considered for tender evaluation must be compared pairwise. The pairwise comparison means relative importance of criteria is decided. Here pairwise comparison was shown in terms of percentage filling of circle. Table 4 shows us the pairwise comparison of criteria.

c) Last column in the table gives us the normalized values [21] [22] [23] [24] [25] [35] [36].

d) Similarly pairwise comparison among attributes considered is done for both dual and triple dimensionalities. New membership grades were obtained using equation 3, 4, and 5. Table 5 and table 6 shows us the pairwise comparison for both cases (dual and triple dimensionalities)

TABLE IV

PAIRWISE COMPARISON OF CRITERIA (SINGLE DIMENSIONALITY)

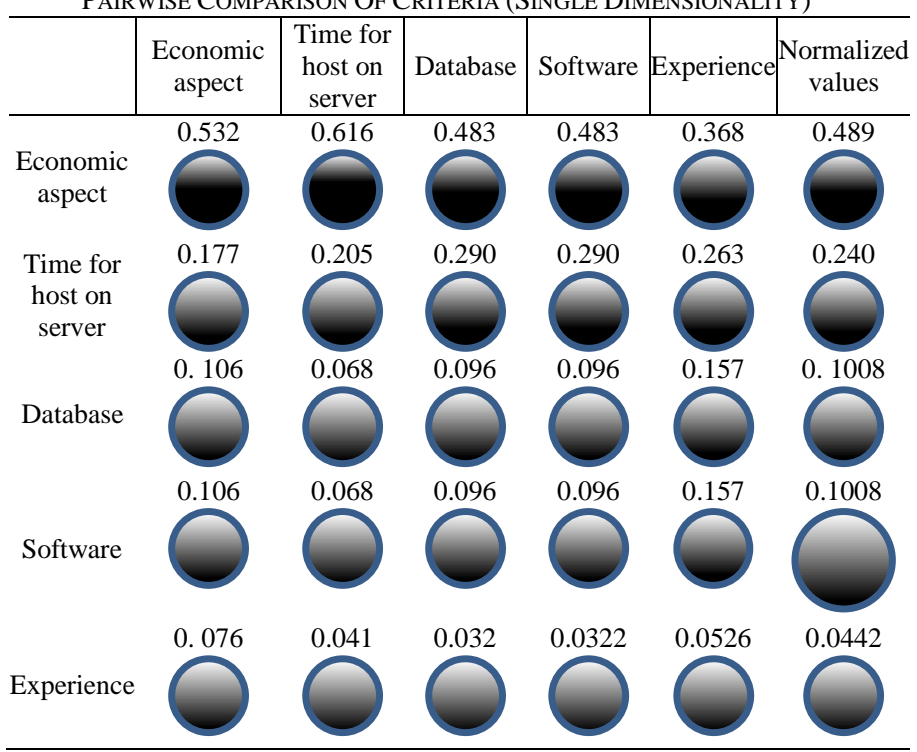


TABLE V

PAIRWISE COMPARISON OF CRITERIA (DUAL DIMENSIONALITY)

\begin{tabular}{|c|c|c|c|c|c|c|}
\hline & $\begin{array}{c}\text { Economic } \\
\text { aspect }\end{array}$ & $\begin{array}{l}\text { Time for } \\
\text { host on } \\
\text { server }\end{array}$ & Database & Software & Experience & $\begin{array}{c}\text { Normalized } \\
\text { values }\end{array}$ \\
\hline $\begin{array}{c}\text { Economic } \\
\text { aspect }\end{array}$ & 0.59 & 0.67 & 0.55 & 0.55 & $\overbrace{}^{0.45}$ & 0.557 \\
\hline $\begin{array}{l}\text { Time for } \\
\text { host on } \\
\text { server }\end{array}$ & & & & & & 0.328 \\
\hline Database & & & & & & \\
\hline Software & & & 0.18 & 0.18 & 0.24 & \\
\hline Experience & & & & & 0.12 & \\
\hline
\end{tabular}

TABLE VI

PAIR WISE COMPARISON OF CRITERIA (TRIPLE DIMENSIONALITY)

\begin{tabular}{l|c|c|c|c|c|c}
\hline & $\begin{array}{c}\text { Economic } \\
\text { aspect }\end{array}$ & $\begin{array}{c}\text { Time for } \\
\text { host on } \\
\text { server }\end{array}$ & Database & Software & Experience & $\begin{array}{c}\text { Normalized } \\
\text { values }\end{array}$ \\
\hline $\begin{array}{c}\text { Economic } \\
\text { aspect }\end{array}$ & 0.647 & 0.717 & 0.606 & 0.606 & 0.510 & 0.613 \\
$\begin{array}{c}\text { Time for } \\
\text { host on } \\
\text { server }\end{array}$ & & & & & & \\
Database
\end{tabular}

g) Now after the pairwise comparison among attributes, similar to the Analytical Hierarchy Process tenderers are compared pairwise for each attributes considered. Table $7,8,9,10,11$ shows the pairwise comparison results for Economic aspect, Time for host on server, Database, Software, Experience respectively in the case of single dimensionality [11] [27] [28] [34].

h) Pairwise comparison of tenderers for each criterion in case of dual and triple dimensionality can be done similarly [29] [30] [31] [32].

TABLE VII

PAIRWISE COMPARISON OF TENDERERS

\begin{tabular}{|c|c|c|c|c|c|}
\hline $\begin{array}{c}\text { Economic } \\
\text { aspect }\end{array}$ & Tender 1 & Tender 2 & Tender 3 & Tender 4 & $\begin{array}{c}\text { Normalized } \\
\text { values }\end{array}$ \\
\hline \multicolumn{6}{|l|}{ Tender 1} \\
\hline \multicolumn{6}{|l|}{ Tender 2} \\
\hline \multicolumn{6}{|l|}{ Tender 3} \\
\hline & 0.642 & 0.5 & 0.5 & 0.576 & 0.551 \\
\hline Tender 4 & & & & & \\
\hline
\end{tabular}

TABLE VIII

PAIR WISE COMPARISON OF TENDERERS

\begin{tabular}{c|c|c|c|c|c}
\hline $\begin{array}{c}\text { Time for } \\
\text { host on } \\
\text { server }\end{array}$ & Tender 1 & Tender 2 & Tender 3 & Tender 4 & $\begin{array}{c}\text { Normalized } \\
\text { values }\end{array}$ \\
\hline Tender 1 & & & & & \\
\hline
\end{tabular}

TABLE IX

PAIRWISE COMPARISON OF TENDERERS

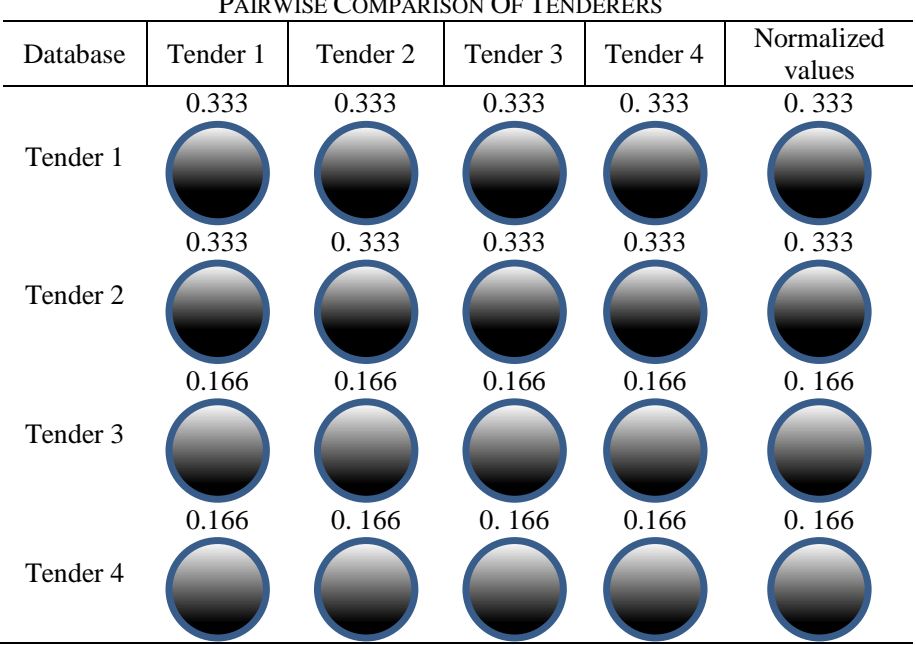

TABLE X

PAIRWISE COMPARISON OF TENDERERS

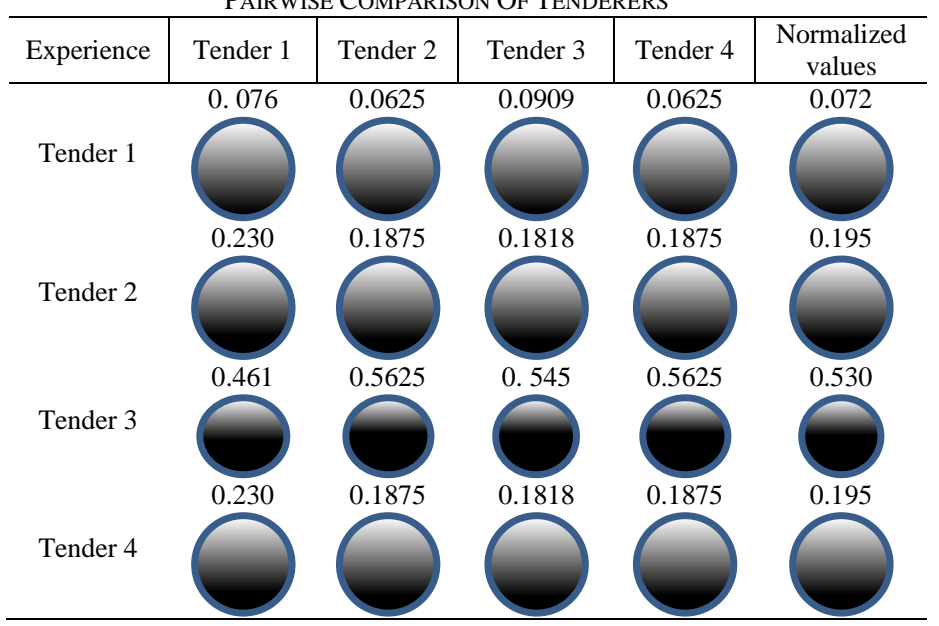


TABLE XI

PAIRWISE COMPARISON OF TENDERERS

\begin{tabular}{l|c|c|c|c|c}
\hline Software & Tender 1 & Tender2 & Tender 3 & Tender 4 & $\begin{array}{c}\text { Normalized } \\
\text { values }\end{array}$ \\
\hline Tender 1 & & & & & \\
Tender 2
\end{tabular}

i. The final result was obtained by the technique followed in Analytical Hierarchy Process. Table 12 shows the final results for all the three cases (single, dual and triple).

TABLE XII

Final Results In All Three Dimensions

\begin{tabular}{|c|c|c|c|c|}
\hline $\begin{array}{c}\text { Company } \\
\text { Result }\end{array}$ & $\begin{array}{c}\text { Single } \\
\text { dimension }\end{array}$ & Dual dimension & Triple dimension & Rank \\
\hline Tender 1 & 0.216 & 0.411 & 0.610 & 3 \\
\hline Tender 2 & 0.284 & 0.511 & 0.734 & 2 \\
\hline Tender 3 & 0.108 & 0.271 & 0.428 & 4 \\
\hline Tender 4 & 0.354 & 0.552 & 0.760 & 1 \\
\hline
\end{tabular}

\section{CASE STUdY - 2}

BITS Pilani is one of the premier technical and science institutes for higher education in India, located at Pilani, India. They planned to construct a new campus in Hyderabad, for that they had sent a notice for tender proposals. They received proposals from five companies out of which three were selected for final bidding process. Figure 3 shows us the criteria considered for tender evaluation.

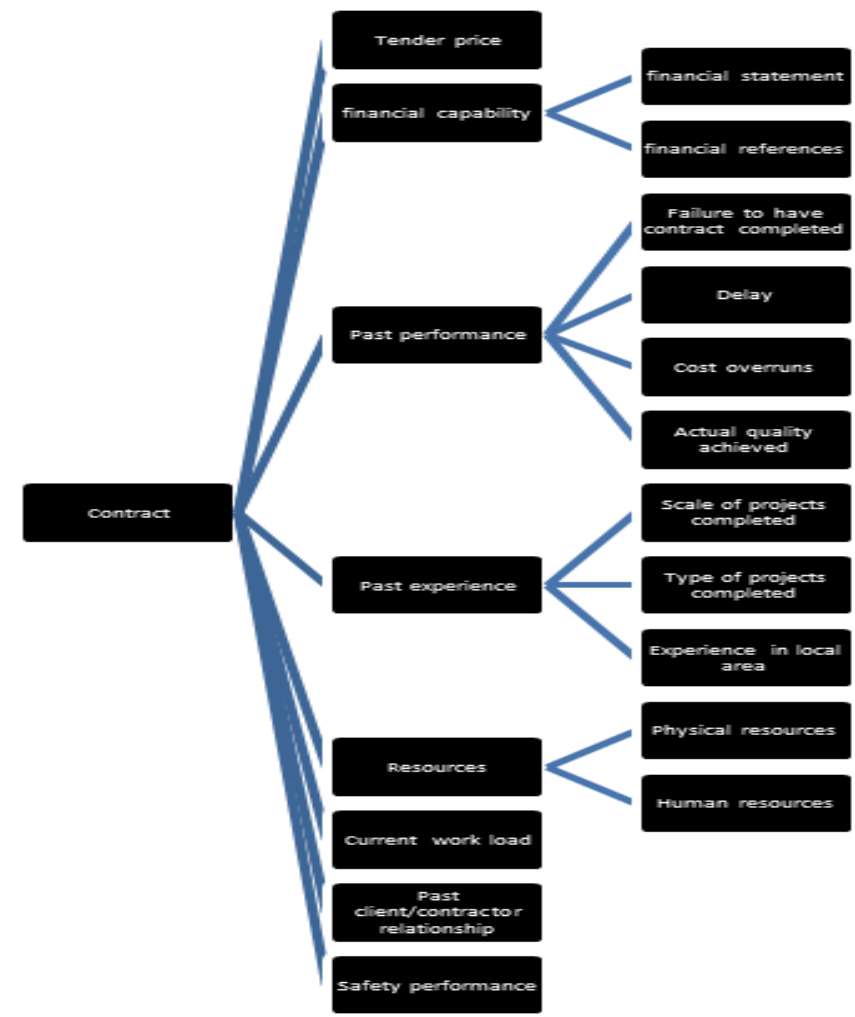

Fig. 3 Attribute chart case study-2

a) Tender evaluation for this case study was solved similar to the previous case study. Table 13, 14, 15 shows us the pairwise comparison of the attributes considered for single, dual, triple dimensionalities [18] [19] [20][35].

TABLE XIII

PAIRWISE COMPARISON OF ATTRIBUTES (SINGLE DIMENSIONALITY)

\begin{tabular}{l|c|c|c|c|c|c|c|c|c}
\hline Criterion & $\begin{array}{c}\text { Tender } \\
\text { price }\end{array}$ & $\begin{array}{c}\text { Financ } \\
\text { ial } \\
\text { capabil } \\
\text { ity }\end{array}$ & $\begin{array}{c}\text { Past } \\
\text { perfor- } \\
\text { mance }\end{array}$ & $\begin{array}{c}\text { Past } \\
\text { experi- } \\
\text { ence }\end{array}$ & $\begin{array}{c}\text { Resourc } \\
\text { es }\end{array}$ & $\begin{array}{c}\text { Past } \\
\text { Worklo } \\
\text { ad } \\
\text { alient/ } \\
\text { contract } \\
\text { or } \\
\text { relations } \\
\text { hip }\end{array}$ & $\begin{array}{c}\text { Safety } \\
\text { Perfor } \\
- \\
\text { manc } \\
\text { enc }\end{array}$ & $\begin{array}{c}\text { Priority } \\
\text { vector }\end{array}$ \\
\hline
\end{tabular}

Tender price

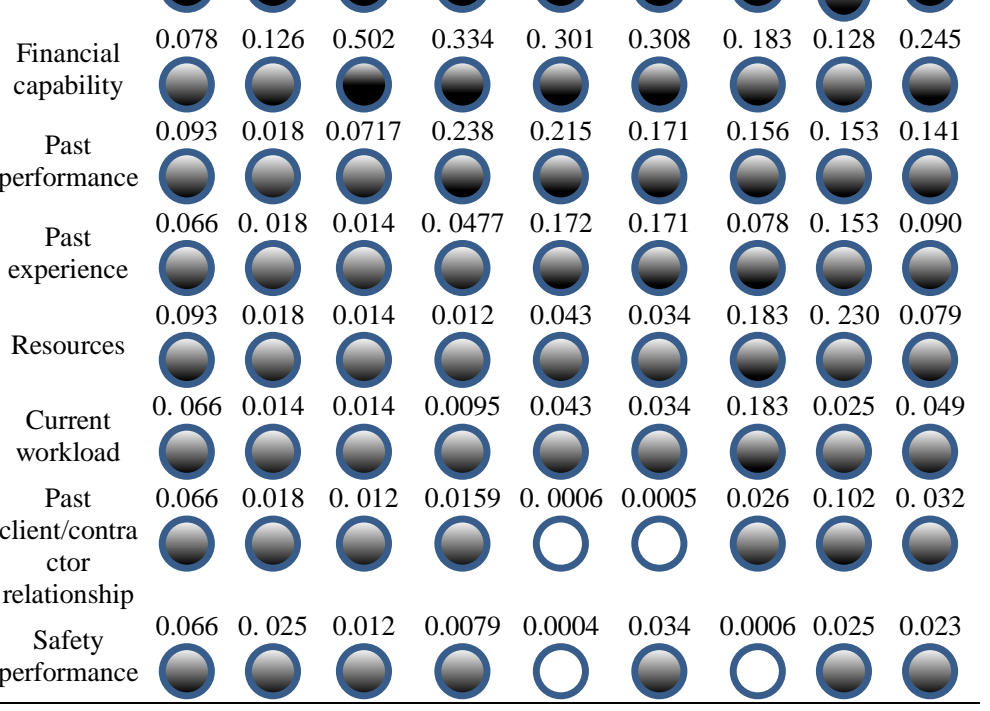


TABLE XIV

PAIRWISE COMPARISON OF ATTRIBUTES (DUAL DIMENSIONALITY)

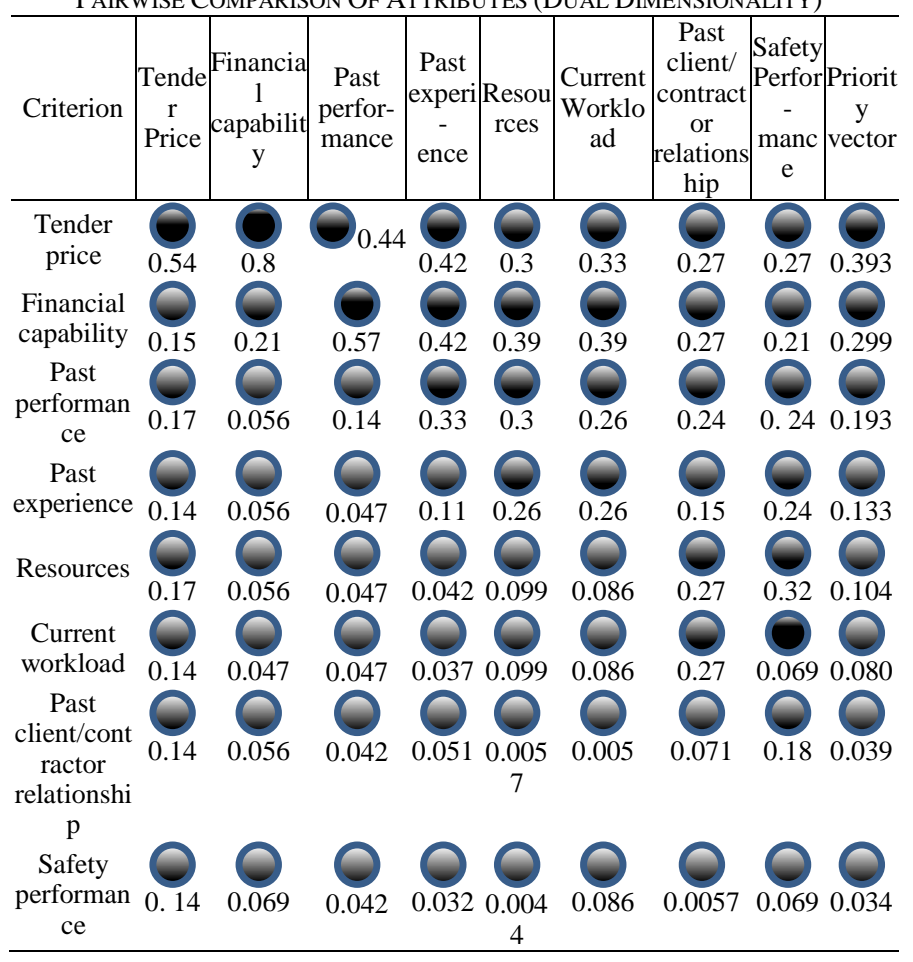

TABLE XV

PAIRWISE COMPARISON OF ATTRIBUTES (TRIPLE DIMENSIONALITY)

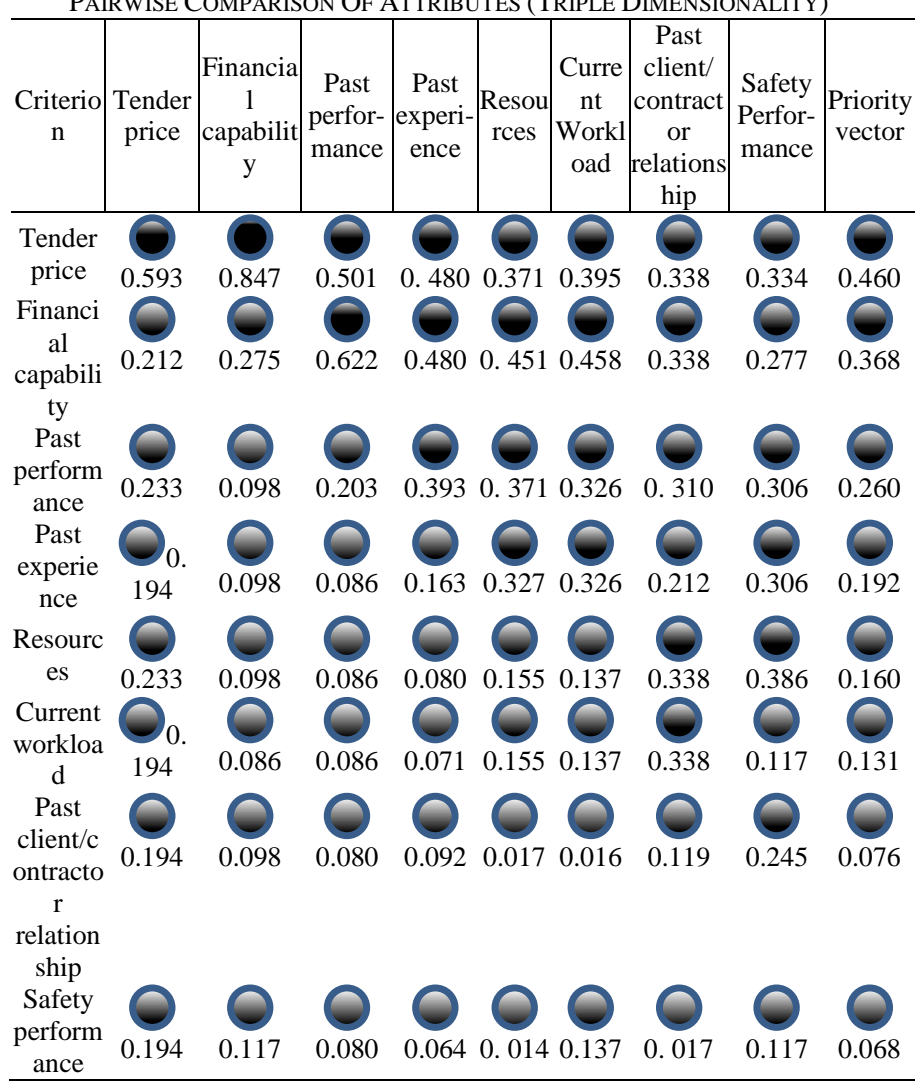

b) Further procedure is carried on as shown in previous case study, the final results are shown below.
TABLE XVI

Final Result OF CASE Study-2

\begin{tabular}{l|c|c|c|c}
\hline Bidder & $\begin{array}{c}\text { One } \\
\text { dimensionality }\end{array}$ & $\begin{array}{c}\text { Dual } \\
\text { dimensionality }\end{array}$ & $\begin{array}{c}\text { Triple } \\
\text { dimensionality }\end{array}$ & Rank \\
\hline Bid 1 & & & & \\
Bid 2 & & & &
\end{tabular}

\section{RESULTS AND DISCUSSION}

Here in the above two case studies we observe that membership grades for three dimension case is more than that in two dimension and membership grades in two dimension is more than one dimension case. Thus membership grade go on increasing with diameter of circle.

Though the membership grades are different results are same in all the three cases. Thus we can state that in case of linearity and nonlinearity results will be same. From the above two case studies it was clear that Tender- 4 got the contract in Case study 1 and Bidder-2 got the contract in Case study-2 (Table 12, 16).

\section{CONCLUSION}

Tender evaluation is one of the main activities and decisions made by the clients. In order to ensure that the project can be completed successfully, the client must evaluate the tender. We proposed a framework for visual decision support system in order to improve tender assessment process as well as help the decision maker to evaluate the best tender more precisely. A decision maker may be willing or able to provide only incomplete, imprecise and vague information because of time pressure, a lack of data or shortcomings in expertise when evaluating tenders against a pre-determined set of criteria. This approach is able to tackle these problems and can help decision makers reach a robust decision although some data may be missing and or assessments may be incomplete.

\section{REFERENCES}

[1]. M. Ganesh, Introduction to Fuzzy sets and Fuzzy logic, Vol. 1, June 2009.

[2]. Patrik Sik-Wah Fong, Sonia kit-yung Choi, Final Contractor selection using the Analytical hierarchy process, Honkong 1999.

[3]. Ting-Ya Hsieh, Fuzzy MCDM approach for planning and design tenders selection in public office buildings, Taiwan 2004.

[4]. Chin Torng-Lin, Bid/no bid decision making-a fuzzy linguistic approach, Taiwan 2004.

[5]. Timothy J. Ross, Fuzzy logic with Engineering Applications, Second Edition, Mexico USA.

[6]. M. Hellman, Fuzzy Logic Introduction, France 2003.

[7]. L.A. Jadeh, Fuzzy sets, Information and control, 1965.

[8]. L.A. Jadeh, Outline of a new approach to the Analysis of complex systems and decision process, 1973.

[9]. M. Ravanshadnia, A comprehensive Bid/no bid decision making framework for construction companies, Iran 2011.

[10]. Jan Jantzen, Tutorial on Fuzzy Logic, Denmark, 2008.

[11]. Rajiv Gupta, Design and development of online database for Aakash Ganga Rainwater Harvesting network, India 2013. 
[12]. Wen-der Yu, Pricing strategy for best value Tender, ASCE 2013.

[13]. Samuel Laryea, Nature of tender review meetings, United Kingdom, 2013.

[14]. Mohan M. Kumaraswamy, Systematizing Construction project evaluations, 1996.

[15]. Hampson Keith, Strategic alliances in Building construction, Australia, 1997.

[16]. Runeson Goran, Tendering theory revisited, Sydney 1999.

[17]. Ian Turner, An independent system for the evaluation of contract tenders, 1988.

[18]. Chandra shekhar Prasad, Government of India Central Public Works department, India 2012.

[19]. Procurement Lawyer's Association, Issues in evaluating Public sector tenders, United Kingdom, June 2010.

[20]. Sebastian Zimmer, Industry project evaluation with the Analytic hierarchy process, Germany.

[21]. Salem Yousef Al Wahaidi, An Analytical Hierarchy process based prequalification for Gaza strip construction contractors, 2012.

[22]. Ade A Oladapo, Tender evaluation methods in construction projects: a comparative case study, 2006.

[23]. Rahul N. Sompura, Scrutiny of tender for award of contracts, Ahmedabad India.

[24]. Noraida Haji Ali, Rating and ranking criteria for selected islands using Fuzzy Analytical hierarchy process, 2012.

[25]. Jingmin Wang, Research on EPC project risk evaluation based on FAHP and TOPSIS, China 2013.

[26]. Chia Chi Sun, A performance integrated model by integrating fuzzy AHP and fuzzy TOPSIS methods, Taiwan 22010.

[27]. Maryam Kordi, Comparison of fuzzy and crisp analytic hierarchy process methods for spatial multi criteria decision analysis in GIS, 2008.

[28]. Mehdi Ziaei, A GIS based multicriteria Evaluation/selection analysis, Iran.

[29]. Ali Asghar Anvary Rostamy, Using fuzzy analytic hierarchy process to evaluate main dimensions of business process reengineering, Iran 2012.

[30]. Askm Ozdagoglu, Comparison of AHP and fuzzy AHP for the multicriteria decision making process with linguistic evaluations, 2007.

[31]. Noor Maizura Mohamad Noor, Fuzzy Analytic Heirarchy Process approach for Evaluating Tourism islands in Terengganu, Malaysia, 2012.

[32]. Han-chen Huang, Weighted analysis on Evaluation criteria of the most advantageous bid, Taiwan 2012.

[33]. Van Uu Nguyen, Tender Evaluation by fuzzy sets, 1985

[34]. Shou Qing Wang, Evaluation and competitive tendering of BOT Power plant project in China, 1998.

[35]. Smita Sarker, Study of influencing factors of tender evaluation: an Evidential Reasoning approach, 2012.

[36]. Panos L. Lorentziadis, Post objective determination of weights of the evaluation factors in public procurement tenders, 2010. 